\title{
Consideraciones del Consejo de Estado sobre el contrato de concesión de obra pública en la nueva Ley de Contratos del Sector Público de 2017
}

\author{
Moisés Barrio Andrés \\ Letrado del Consejo de Estado \\ moises.barrio@consejo-estado.es / @moisesbarrioa
}

\begin{abstract}
NOTA BIOGRÁFICA
Letrado del Consejo de Estado, Doctor en Derecho y Profesor de Derecho Administrativo. Académico correspondiente de la Real Academia de Jurisprudencia y Legislación. Asesor de distintas Administraciones Públicas, en España y en Hispanoamérica, en materias de Derecho de Internet y Derecho Público. Secretario de la Revista Documentación Administrativa, del Seminario sobre la Reforma del Estado dirigido por el prof. Muñoz Machado y del Foro de Debate Jurídico. Especialista en Derecho de Internet y de las TIC, así como en Derecho Público económico y contratación administrativa. Es autor de múltiples publicaciones individuales y colectivas en el campo del Derecho de Internet, propiedad intelectual, nuevas tecnologías y Derecho Público económico. Su último libro publicado es Fundamentos del Derecho de Internet (Editorial Centro de Estudios Políticos y Constitucionales, Madrid, 2017).
\end{abstract}

\section{SUMARIO}

I. INTRODUCCIÓN. II. LOS NUEVOS CONTORNOS DEL CONTRATO DE CONCESIÓN DE OBRA PÚBLICA. III. CONCLUSIÓN.

\section{INTRODUCCIÓN}

Como se sabe, el contrato de "concesión de obra pública» es aquel en cuya virtud el contratista realiza las prestaciones propias de un contrato de obras percibiendo como contraprestación el derecho a explotar la obra, y en su caso, un precio. Esta figura contractual ${ }^{1}$ nace con la finalidad de lograr interesar a la iniciativa privada en la ejecución de obras e infraestructuras que, por su elevado coste económico, suponen una gravosa carga para el Erario público. En este contexto, las Administraciones Públicas se ven obligadas a conciliar el rigor derivado de los objetivos y condicionamientos macroeconómicos de la Unión Europea ${ }^{2}$, con la necesidad de completar o, en su caso, ampliar las redes de obras e infraestructuras públicas, siendo así que en la búsqueda de nuevos instrumentos financieros y de gestión aparece como una necesidad el recurso a la participación y al capital privado.

1 Sobre la misma, vid. P. GARCÍA GARCÍA, Las concesiones administrativas de carreteras en el ordenamiento jurídico español. Madrid: Ministerio de Obras Publicas y Urbanismo, 1979; A. MENÉNDEZ MENÉNDEZ, Comentarios a la nueva Ley 13/2003, de 23 de mayo, reguladora del contrato de concesión de obras públicas. Madrid: Cívitas, 2003; A. EMBID IRUJO, Comentarios a la Ley reguladora del contrato de concesión de obras públicas. Navarra: Aranzadi, 2004; A. RUIZ OJEDA, La concesión de obra pública. Madrid: Cívitas, 2006; A. CASARES MARCOS, La concesión de obras públicas a iniciativa particular: tramitación, adjudicación y garantía contractual de la calidad. Madrid: Montecorvo, 2007; F. PUERTA SEGUIDO, El contrato de concesión de obras públicas en la Ley de Contratos del Sector Público. Madrid: La Ley, 2009; A. MENÉNDEZ MENÉNDEZ, Instrumentos españoles de colaboración público-privada: el contrato de concesión de obras públicas. Madrid: Cívitas, 2010; o D. BLANQUER CRIADO, Los contratos del sector público. Valencia: Tirant lo Blanch, 2013.

2 Sobre estas transformaciones, vid. M. BARRIO ANDRÉS, "La nueva actividad regulatoria de la Administración", en Revista General de Legislación y Jurisprudencia, núm. 1/2018. 
Los orígenes del contrato de concesión de obra pública, y prescindiendo de antecedentes históricos más remotos como la ejecución y explotación de obras públicas hidráulicas en el Canal Imperial de Aragón en 1538, pueden rastrearse en la Instrucción para promover y ejecutar las obras públicas, aprobada por el Real Decreto de 10 de octubre de 1845. Esta norma estableció una regulación mínima inicial de la figura. Después, la Ley General de Obras Públicas de 13 de abril de 1877 la reguló con un mayor detalle, pero también de forma insuficiente.

Sin embargo, en la Ley de Contratos del Estado de 8 de abril de 1965 se omitió su regulación, aunque la Ley 8/1972, de 10 de mayo, de construcción, conservación y explotación de autopistas en régimen de concesión restauró esta figura pero con carácter sectorial, reservándola a las autopistas en régimen de peaje. Habrá que esperar a la Ley 13/1995, de 18 de mayo, de Contratos de las Administraciones Públicas para su tímida recuperación con carácter general, aunque el régimen se limitaba a establecer, en síntesis, determinados requisitos en materia de publicidad y concurrencia por imperativo de la Directiva 93/37/CEE del Consejo, de 14 de junio de 1993, sobre coordinación de los procedimientos de adjudicación de los contratos públicos de obras, sin ocuparse de instituir un régimen integral. Será finalmente con la Ley 13/2003, de 23 de mayo, reguladora del contrato de concesión de obras públicas, cuando esta modalidad contractual adquiera carta de naturaleza definitiva. Asimismo, una especie de este tipo de contrato lo constituye el contrato de concesión de obras hidráulicas destinadas a la protección, control y aprovechamiento de las aguas continentales y del dominio público hidráulico, regulado en los artículos 133 a 135 del texto refundido de la Ley de Aguas, aprobado por Real Decreto Legislativo 1/2001, de 20 de julio.

Por su parte, el Consejo de Estado $^{3}$ ha desempeñado un papel destacado en la reforma de la legislación sobre contratos públicos. En el ejercicio de su función consultiva, el Consejo de Estado ha participado en el procedimiento de elaboración de las normas jurídicas a través de las cuales dicha reforma se ha forjado, destacando a este respecto el dictamen 1.116/2015, de 10 de marzo de 2016, sobre el Anteproyecto de Ley de Contratos del Sector Público, y el dictamen 1.115/2015, de idéntica fecha, relativo al Anteproyecto de Ley sobre procedimientos de contratación en los sectores del agua, la energía, los transportes y los servicios postales.

Del mismo modo, el Consejo de Estado ha tenido ocasión de llamar la atención en diversas ocasiones sobre las transformaciones del concepto de contrato de concesión de obra pública. Lo hizo ya en los dictámenes 923/1997, de 5 de junio, 3.375/2001, de 5 de diciembre, 3.205/2003, de 20 de noviembre, 635/2005, de 5 de mayo, o 660/2014, de 17 de diciembre, y lo ha realizado de nuevo en 2016 al emitir los señalados dictámenes de 10 de marzo de 2016 que tuvieron como objeto los precitados anteproyectos de ley de los comúnmente denominados sectores excluidos y contratos del sector público respectivamente. A examinar su doctrina al respecto dedicaremos las próximas páginas.

\section{LOS NUEVOS CONTORNOS DEL CONTRATO DE CONCESIÓN DE OBRA PÚBLICA}

En el contrato de obras, el contratista construye la obra y la entrega por un precio a la Administración, quien la explota. En la concesión de obras, además de construirlas, el contratista la financia y explota durante un período, compensándose de la inversión por los precios que obtiene de los usuarios o de las cantidades abonadas por la Administración. Por ello, como puso de manifiesto el Consejo de Estado en reiteradas ocasiones (por todas, los dictámenes números 4.464/98, de 22 de diciembre y 3.375/2001, de 5 de diciembre) -y también han subrayado tanto la doctrina como la jurisprudencia-, este tipo de concesión tiene un carácter mixto en el que indisolublemente se presentan perfiles propios de la concesión de obra pública y de servicio público, constituyendo un tipo intermedio. Los primeros perfiles se hacen especialmente patentes en la fase de construcción de la obra, y los segundos en la fase de explotación y conservación.

El artículo 14 de la Ley 9/2017, de 8 de noviembre, de Contratos del Sector Público, por la que se transponen al ordenamiento jurídico español las Directivas del Parlamento Europeo y del Consejo 2014/23/UE y 2014/24/UE, de 26 de febrero de 2014 (abreviadamente LCSP2017) define el contrato de concesión de obras. En concreto, en su apartado 1, se establece que «[l]a concesión de obras es un contrato que tiene por objeto la realización por el concesionario de algunas de las prestaciones a que se refiere el artículo anterior

Sobre la posición vigente y papel actual del Consejo de Estado nos hemos ocupado en otro trabajo: M. BARRIO ANDRÉS, "EI Consejo de Estado: institución de tradición y de progreso", en J. M. BAÑO LEÓN (coord.), Memorial para la reforma del Estado: Estudios en homenaje al Profesor Santiago Muñoz Machado. Madrid: Centro de Estudios Políticos y Constitucionales, 2016. 
[que define el contrato de obras], incluidas las de restauración y reparación de construcciones existentes, así como la conservación y mantenimiento de los elementos construidos, y en el que la contraprestación a favor de aquel consiste, o bien únicamente en el derecho a explotar la obra en el sentido del apartado cuarto siguiente, o bien en dicho derecho acompañado del de percibir un precio».

La nueva regulación que contiene la recién publicada Ley de Contratos del Sector Público de 2017 presenta perfiles diferenciadores del contrato de concesión de obra pública clásica, cuyos orígenes modernos se detectan, según quedó ya apuntado, en la Instrucción para promover y ejecutar las obras públicas, aprobada por el Real Decreto de 10 de octubre de 1845. En efecto, en su configuración histórica, la explotación de la obra era la contraprestación que recibía el concesionario por su construcción y dicha explotación se hacía a su riesgo y ventura, si bien éste podía mitigarse -e incluso llegar a casi suprimirse- mediante la articulación de diversos mecanismos.

La regulación ahora promulgada altera estas dos reglas básicas tradicionales, como subraya el propio Consejo de Estado. En primer término, junto al hecho de que la explotación de la obra pueda ser la contraprestación que recibe el concesionario por su construcción, la nueva regulación permite que la explotación sea el objeto mismo de la concesión. Esta configuración no era extraña a nuestro ordenamiento jurídico, por cuanto estaba ya habilitada en la Ley 8/1972, de 10 de mayo, de construcción y explotación de autopistas en régimen de concesión, pero no tenía carácter general.

La singularidad de que la explotación de la obra no sea sólo la contraprestación que recibe el concesionario por su construcción, sino que constituya su objeto mismo, tiene como consecuencia que la duración y las condiciones técnicas y económicas de la explotación no tienen como condición retribuir estrictamente la obra hecha, sino que adquieren autonomía que la hacen partícipe de determinadas características de la concesión de los servicios. Se trata, en síntesis, de un contrato con un doble contenido: la realización de una obra y su explotación. En sus inicios, es un contrato que participa de las características del de obra y que sólo cuando concluye adquiere algunos perfiles propios del antiguo contrato de gestión de los servicios públicos a los efectos de la obligación del contratista. Esta característica hace que la retribución que puede percibir el concesionario por la prestación del servicio no esté ni limitada por el valor de la obra pública construida, ni asegurada su compensación.

En esta última circunstancia, en que el concesionario de obra pública no tenga asegurada la recuperación de las inversiones hechas ni el pago de los costes en que haya incurrido, se concreta la introducción como elemento definidor de la figura inédita del llamado «riesgo operacional» (artículo 14.4 LCSP2017). Es esta la segunda alteración de las reglas básicas tradicionales.

En el concepto clásico, la concesión de obra pública pivota sobre su configuración como una locatio operis que no es sino la expresión normal de la articulación de las prestaciones en el arrendamiento de obra: resultado contra precio fijo o alzado. En otros términos, su esencia radica en el riesgo y ventura que asume el contratista, y que significa tres cosas: que la mayor o menor onerosidad sobrevenida no autoriza al contratista a desligarse del contrato; que no le da derecho a pretender su modificación; y, en fin, que los riesgos anteriores al pago han de ser soportados por el propio contratista. No obstante, el principio de riesgo y ventura -que alcanza su plenitud para la construcción de la obra pública- cede en la fase de gestión, pues prevalecen en ella otros perfiles más propios del servicio público. Queda modulado por la idea de compensación económica (equilibrio económico-financiero), hasta el punto de ser uno de los elementos caracterizadores básicos de la figura.

El equilibrio económico de la concesión administrativa es un concepto jurídico indeterminado que informa y caracteriza las relaciones entre la Administración concedente y el concesionario privado no como un mero intercambio de prestaciones sino como una forma de colaboración para la consecución de un mismo fin. Se justifica, como recuerda el dictamen 108/2017, de 1 de junio, en el interés público al que atiende el servicio objeto de aquélla. Como consecuencia de ello, el equilibrio económico en el seno de una concesión asegura la conmutatividad de las prestaciones y la existencia de una igualdad entre las ventajas que se conceden al concesionario y las obligaciones que le son impuestas en consonancia con la "honesta equivalencia entre lo que se concede al concesionario y lo que se le exige" (Arrêt de 11 de marzo de 1910, del Consejo de Estado francés, Compagnie Générale Française des Tramways -arrêt Blum ${ }^{4}-$ ). El equilibrio económico despliega su eficacia en relación con ambas partes -frente a concepciones trasnochadas que lo ceñían a favor del concesionario- como evidencian los hasta ahora vigentes artículos 258 y 282 del texto refundido de la Ley de Contratos del Sector Público, aprobado por Real Decreto Legislativo 3/2011, de 14 de noviembre.

4 Disponible en https://www.legifrance.gouv.fr/affichJuriAdmin.do?idTexte=CETATEXT000007635472. 
Ambas nociones -riesgo y ventura y equilibrio económico financiero- no son incompatibles. Antes al contrario, juegan coordinadamente en el ámbito de las concesiones; con una mayor intensidad en las de servicio público y mixtas de obra y servicio público, como son las de autopistas y, en una menor intensidad, en las de obra pública. En efecto, el equilibrio económico constituye un mecanismo que tiene su límite natural en el riesgo y ventura, que sigue constituyendo el elemento definidor básico de la institución concesional. El juego de ambos asegura la vigencia de los principios de reciprocidad, conmutatividad, equivalencia de prestaciones, rendimiento económico para la Administración y el de proporcionalidad entre las prestaciones debidas (Sentencia del Tribunal Supremo de 28 de julio de 1998). El riesgo y ventura impide que el equilibrio económico se convierta en una garantía ordinaria total de los intereses de la empresa, trasladándolos íntegros al Erario público en contra de lo que constituye la esencia misma de la institución y sus límites naturales, como ha señalado la Sentencia del Tribunal Supremo de 9 de octubre de 1987.

Lo que no cabe en este esquema legal hasta hoy vigente, por tanto, es la inexistencia -de manera absoluta- del riesgo y ventura y su sustitución por una aplicación del equilibrio económico que lo deje sin efecto. Así lo puso de manifiesto la exposición de motivos de la Ley 13/2003, de 23 de mayo, reguladora del Contrato de Concesión de obras públicas, al decir "la asunción de riesgo en "proporción sustancial" por el concesionario resulta determinante para que el contrato de concesión merezca tal calificación», y lo ha advertido el Consejo de Estado en varias ocasiones (entre otros, el precitado dictamen 3.375/2001, de 5 de diciembre y en los dictámenes de 10 de marzo de 2016). Y es que la supresión del riesgo y ventura «ha sido puesta en cuestión doctrinalmente, al estimar, con toda justicia, que hay que dejar a cargo del concesionario lo que se ha llamado el "alea normal del contrato", es decir, la pérdida o el beneficio que hubiera podido preverse normalmente, ya que un seguro total, que garantice al concesionario de todos los riesgos eventuales de la empresa y los traslade a la Administración en su integridad, vendría a establecer un desequilibrio y, en esta hipótesis, contrario a los intereses públicos y a los principios de la justicia eterna (SSTS de 2 de julio de 1873 y de 25 de marzo de 1915), lo que representa un interpretación que conduce al absurdo» (Sentencia del Tribunal Supremo de 24 de abril de 1985). La inexistencia completa del riesgo y ventura en una relación concesional comporta, en consecuencia, que no se esté ante tal figura sino ante otra distinta; en concreto, ante un contrato de servicios.

En el esquema señalado, recuerda el Consejo de Estado, sin embargo el riesgo es compatible con la asunción por parte del Estado del coste de explotación de la concesión con el fin de disminuir el precio que debe pagar el usuario. Ahora bien, esta remuneración no puede tener el efecto de eliminar el riesgo de explotación que corresponde al concesionario, so pena de su recalificación como contrato. El riesgo tiene, por otra parte, de ordinario su límite en la no pérdida, esto es, en la compensación de la inversión efectuada. Lo que no puede asegurarse es un beneficio, un rendimiento positivo, al concesionario desvinculado causalmente del uso efectivo de la infraestructura. El concesionario puede ver ceñido su beneficio a lo que es la recuperación del coste de la inversión efectuada. En otros términos, aunque la vinculación de las remuneraciones al operador económico por el uso o frecuencia del servicio sea un elemento significativo, lo determinante para apreciar la existencia de una concesión de servicios es que se haya transferido al concesionario la responsabilidad de la explotación. En consecuencia, en los casos en que la retribución al concesionario está vinculada al uso del servicio, pero existen mecanismos de compensación por los que el poder público garantiza un nivel de beneficios no cabe hablar de la existencia de una concesión si desaparece el riesgo de explotación. Depende de la existencia de riesgo de explotación el que el contrato sea de concesión o, en su ausencia efectiva, de servicios.

Pues bien, el esquema expuesto se ve radicalmente modificado en la regulación de la LCSP2017 a resultas de la incorporación de las previsiones de la Directiva 2014/23/UE, del Parlamento Europeo y del Consejo, de 16 de febrero, de 2014, relativa a la adjudicación de contratos de concesión.

El artículo 2.1.a) de esta Directiva define la concesión de obras públicas como «un contrato oneroso celebrado por escrito, en virtud del cual uno o más poderes o entidades adjudicadores confían la ejecución de obras a uno o más operadores económicos, cuya contrapartida es bien el derecho a explotar las obras objeto del contrato únicamente, o este mismo derecho en conjunción con un pago».

El apartado b) del mismo precepto define la concesión de servicios como «un contrato oneroso celebrado por escrito, en virtud del cual uno o más poderes o entidades adjudicadores confían la prestación y la gestión de servicios distintos de la ejecución de las obras contempladas en la letra a) a uno o más operadores económicos, cuya contrapartida es bien el derecho a explotar los servicios objeto del contrato únicamente, o este mismo derecho en conjunción con un pago».

Y el párrafo segundo del precepto añade que «[l]a adjudicación de las concesiones de obras o servicios implicará la transferencia al concesionario de un riesgo operacional en la explotación de dichas obras o 
servicios abarcando el riesgo de demanda o el de suministro, o ambos. Se considerará que el concesionario asume un riesgo operacional cuando no esté garantizado que, en condiciones normales de funcionamiento, vaya a recuperar las inversiones realizadas ni a cubrir los costes que haya contraído para explotar las obras o los servicios que sean objeto de concesión. La parte de los riesgos transferidos al concesionario supondrá una exposición real a las incertidumbres del mercado que implique que cualquier pérdida potencial estimada en que incurra el concesionario no es meramente nominal o desdeñable».

Conforme con la Directiva -que ha recogido en este punto la jurisprudencia comunitaria consolidada sobre la materia (SSTJUE de 10 de septiembre de 2009, asunto Eurwasser, de 10 de marzo de 2011, asunto Privater Rettungsdienst, y de 10 de noviembre de 2011, asunto Norma-A y Dekom), con casos procedentes sobre todo de Alemania-, el rasgo diferencial que caracteriza a la concesión frente a otros contratos es la transferencia real del riesgo en la construcción de la obra o la prestación del servicio, de modo que el concesionario pueda no recuperar la inversión realizada o no cubrir los costes de la explotación.

Las previsiones señaladas son incorporadas al artículo 14 de la nueva Ley de Contratos del Sector Público de 2017; en especial, en sus apartados 3 y 4. El Consejo de Estado llamó la atención en su dictamen $1.116 / 2015$ ya citado sobre el hecho de que las nuevas determinaciones trastocan la regulación hasta ahora vigente. Ésta hacía pivotar la figura concesional en el siempre delicado equilibrio entre el riesgo y ventura en la ejecución de la obra y la prestación del servicio y el derecho al equilibrio económico de la concesión. Sin embargo, la regulación recién estrenada va mucho más allá al tomar como gozne de la institución concesional el riesgo operacional. La existencia de un derecho del concesionario al equilibrio económico de la concesión en el Derecho español -de tal manera que el margen de beneficio planteado en el estudio económico-financiero se mantenga estable en términos económicos durante la vida del otorgamiento- choca frontalmente con el concepto de riesgo operacional y por eso desaparece en el nuevo régimen. Este, como se ha dicho, existe cuando no está garantizado que el concesionario vaya a recuperar las inversiones realizadas ni a cubrir los costes, afirmando que la aplicación de la regulación de concesiones es improcedente en los casos en que se alivie al contratista de cualquier pérdida potencial garantizando unos ingresos mínimos iguales o superiores a los costes. A la vista de estas previsiones, la nueva regulación priva al concesionario del derecho al equilibrio económico en los términos tradicionales.

\section{CONCLUSIÓN}

Así las cosas, el Consejo de Estado, aun considerando adecuada la regulación proyectada en el entonces citado Anteproyecto de Ley -y ya por fin Ley publicada en el «BOE» de 9 de noviembre de 2017-, señaló que era conveniente establecer una regulación más detallada del contrato de concesión de obra pública; en especial, en lo tocante a la determinación del cálculo del riesgo de explotación debido a las dificultades apreciadas para fijarlo en diversos casos sobre los que ha tenido ocasión de pronunciarse este Cuerpo Consultivo (v. gr. dictámenes 1.134/2015 y 1.135/2015, ambos de 12 de noviembre). Esta recomendación no se ha plasmado en el texto finalmente remitido a las Cortes Generales, pero el Consejo de Estado la ha reiterado en su Memoria de $2016^{5}$ con el fin de evitar dificultades interpretativas futuras.

\footnotetext{
5 Disponible en http://www.consejo-estado.es/memorias.htm.
} 